\title{
Evaluation of Wound Healing Potential of Novel Hydrogel Based on Ocimum basilicum and Trifolium pratense Extracts
}

\author{
Ina Andreea Antonescu (Mintaș) ${ }^{1}$, Angela Antonescu ${ }^{2}$, Florina Miere (Groza) ${ }^{2, *}$, Luminița Fritea ${ }^{2}$, \\ Alin Cristian Teușdea ${ }^{3, *}$, Laura Vicaș ${ }^{2}{ }^{(0)}$, Simona Ioana Vicaș ${ }^{3}$, Ilarie Brihan ${ }^{2, *}$, Maria Domuța ${ }^{2}$, \\ Mihaela Zdrinca ${ }^{2}$, Marcel Zdrinca ${ }^{2}$ and Simona Cavalu ${ }^{2, * \mathbb{B}}$
}

check for

updates

Citation: Antonescu (Mintaș), I.A.; Antonescu, A.; Miere (Groza), F.;

Fritea, L.; Teușdea, A.C.; Vicaș, L.;

Vicaș, S.I.; Brihan, I.; Domuța, M.;

Zdrinca, M.; et al. Evaluation of

Wound Healing Potential of Novel Hydrogel Based on Ocimum basilicum and Trifolium pratense Extracts. Processes 2021, 9, 2096. https:// doi.org/10.3390/pr9112096

Academic Editor: Michaela Schmitz

Received: 11 October 2021

Accepted: 16 November 2021

Published: 22 November 2021

Publisher's Note: MDPI stays neutral with regard to jurisdictional claims in published maps and institutional affiliations.

Copyright: (c) 2021 by the authors. Licensee MDPI, Basel, Switzerland. This article is an open access article distributed under the terms and conditions of the Creative Commons Attribution (CC BY) license (https:// creativecommons.org/licenses/by/ $4.0 /)$.
1 Faculty of Medicine and Pharmacy, Doctoral School of Biomedical Science, University of Oradea, 10 P-ta 1 December Street, 410073 Oradea, Romania; antonescu.ina@gmail.com

2 Faculty of Medicine and Pharmacy, University of Oradea, 10 P-ta 1 December Street, 410073 Oradea, Romania; angela.antonescu@didactic.uoradea.ro (A.A.); lfritea@uoradea.ro (L.F.); laura.vicas@gmail.com (L.V.); maria.domuta@yahoo.com (M.D.); mzdrinca@uoradea.ro (M.Z.); marcelzdrinca@yahoo.ro (M.Z.)

3 Faculty of Environmental Protection, University of Oradea, 26 Gen. Magheru Street, 410048 Oradea, Romania; svicas@uoradea.ro

* Correspondence: florinamiere@uoradea.ro (F.M.); ateusdea@yahoo.co.uk (A.C.T.); brihan_drm@yahoo.com (I.B.); simona.cavalu@gmail.com (S.C.)

Abstract: Plants are an inexhaustible source of compounds with different medicinal properties, suitable as alternative options for the prevention and treatment of various pathologies. They are safe, effective and economical. In this paper, a combined extract made of Ocimum basilicum and Trifolium pratense extracts (EOT) was used for the first time to demonstrate its healing effect on dermal pathologies. To evaluate the wound healing effect of EOT, a novel gel formulation was prepared and subsequently tested in vitro (using the scratch test assay) and in vivo (on an animal model). The in vitro tests demonstrated the complete recovery of the dermal fibroblast monolayer when treated with EOT in a concentration of $50 \mu \mathrm{g} / \mathrm{mL}$. In vivo results using a hydrogel formulation based on EOT demonstrated improved wound contraction time and complete healing after 13 days of treatment. Moreover, a clinical case of Psoriasis vulgaris was presented, in which one week of treatment led to the significant improvement of the patient's health. In conclusion, the topical use of the novel gel formulation containing EOT is a successful therapeutic alternative in the treatment of dermal diseases.

Keywords: Ocimum basilicum; Trifolium pratense; hydrogel; scratch assay; in vitro and in vivo tests; Psoriasis vulgaris

\section{Introduction}

It is generally accepted that plants and their products possess immense potential for the treatment of wounds and cutaneous inflammations. The demand for herbal dressings is continuously increasing in both developed as well as developing countries, as they are widely available and safer and better tolerated than allopathic drugs, promoting repair mechanisms in a natural way [1,2]. As a huge reservoir of bioactive compounds, herbalderived dressings represent a low-cost alternative for wound healing, in the context of bacterial resistance. Currently used antibiotic-loaded wound dressings are often associated with the overuse of synthetic drugs and the occurrence of bacterial resistance, as well as toxicity and de-pigmentation of the wound area [3]. According to the WHO, it is estimated that $80 \%$ of the world population prefers herbal-based treatments for dermatological diseases, cancer, diabetes and other oxidative-stress related diseases [4].

In this context, a search for new therapeutic options based on plants and their metabolites is required, as a great source of novel and unexplored biomolecules. According to the literature, Ocimum species possess an abundance of phenolic acids, but also volatile oils, while Trifolium species are rich in isoflavones [5-7]. 
Due to the rich chemical composition presented in the literature and the biological activities demonstrated so far, the extracts of Trifolium and Ocimum species are considered beneficial in the treatment of respiratory diseases and fungal or bacterial infections. Currently, there is a growing interest to demonstrate the benefits of these plants in dermal pathologies, based on their rich antioxidant contents [8-11].

In a very recent paper, Antonescu et al. explored the therapeutic potential of Ocimum basilicum and Trifolium pratense in terms of antioxidant, antimicrobial, antiviral, antifungal and anti-inflammatory activity in relation with their phytochemical profiles [12].

The authors identified common, similar and distinct therapeutic effects of Ocimum and Trifolium species [12]. Ocimum species possess multiple therapeutic effects in the areas of respiratory diseases, wound treatment, bacterial or fungal infections, headaches and gastrointestinal disorders. Trifolium species have been documented for their anticancer and antidiabetic properties, and their beneficial effects in treating respiratory diseases, wounds, bacterial or fungal infections, gastrointestinal disorders, menstrual pain and tuberculosis, to mention only a few $[7,12]$. Hence, the potential of both plant extracts to be used in wound healing (including acute and chronic wounds) processes has been hypothesized, based on their similar therapeutic effects. The phytochemical profile of Ocimum basilicum evidenced by the presence of cinnamic, caffeic, ferulic, syringic, p-hydroxybenzoic and chlorogenic acids, along with catechin, rutin, apigenin and quercetin [5,7]. On the other hand, Trifolium pratense contains a substantial amount of isoflavones and flavonoids: biochanin A, genistein, daidzein, quercetin, kaempferol and coumarin, along with phenolic acids such as cinnamic, caffeic, ferulic and syringic acid [7,13]. Based on their rich phenol and flavonoid contents, their antimicrobial effects were demonstrated against Gram-positive bacteria (Streptococcus pyogenes and Staphylococcus aureus), Gram-negative bacteria (Pseudomonas aeruginosa, Escherichia coli) and fungi (Candida albicans) [14-16]. Additionally, the anti-inflammatory and immunomodulatory effects of Ocimum species has been recently evaluated $[17,18]$ and found to reduce the expression of inflammatory cytokine mRNA, including IL-6, IL- $1 \beta$, TNF- $\alpha$ and CCL2, as markers of adipocyte-induced inflammation.

The above-mentioned results are promising in order to develop new formulations devoted to dermal pathology and wound healing, for conditions such as acne, eczema boils, psoriasis and rashes.

Topical formulations suitable for wound healing must reduce pain and be nonadherent, easy to formulate and inexpensive. It would also be ideal for the formula to possess antimicrobial properties, to be easily removed when necessary and to be able to absorb the exudate from the wound. Of the many existing topical formulas, hydrogels possess most of the above properties [19]. Other important features of hydrogels include the promotion of wound contraction and allowing a flow of oxygen to support the respiratory activity of the epithelial cells [20]. Clinical studies have confirmed that moist conditions lead to faster wound contraction and can accelerate wound healing by up to $50 \%$ [21,22]. These studies also observed accelerated cell migration into the wound tissue and faster re-epithelialization.

Depending on their composition, hydrogels can be categorized as natural or synthetic. Hydrophilic polymers are able to absorb a high amount of water, allowing for the formation of a chemically or physically linked three-dimensional network, suitable for treating dry and necrotic wounds Additionally, the polymeric network may include various types of biomolecules or plant extracts to make the healing process more efficient [23].

In this context, the aim of our work was to prepare a novel hydrogel based on extracts from Ocimum basilicum and Trifolium pratense, and to evaluate its wound healing effect in vitro (human dermal fibroblasts) and in vivo (small animal model). Moreover, a clinical case was presented, highlighting the efficiency of the novel hydrogel formulation in the case of Psoriasis vulgaris, also known as chronic stationary psoriasis, or plaque-like psoriasis [24]. To the best of our knowledge, this is the first paper in which the combined effects of these plants are explored in terms of a synergic mechanism to improve the wound healing process. 


\section{Materials and Methods}

\subsection{Preparation of Ocimum basilicum and Trifolium pratense Extracts}

The aerial parts of Trifolium pratense L. and Ocimum basilicum L., collected from N-V Transylvania, Romania, were used for the extract preparation, as previously reported by Antonescu et al., 2019 and Miere (Groza) et al. [7,25]. Briefly, the vegetal material was dried in a drier at $50{ }^{\circ} \mathrm{C}$ for $10 \mathrm{~h}$, then smashed in a medicinal crusher until a fine powder of each vegetal material was obtained. The dried material was mixed in a ratio of 1:1 (w/w), added to a 70\% hydroalcoholic solution (1:10 w/v) under magnetic stirring for $20 \mathrm{~min}$ and then sonicated for $5 \mathrm{~min}$. The hydroalcoholic extract was centrifuged and the supernatant was evaporated in a vacuum using a rotary evaporator. The dry extract was transferred to a vessel containing $10 \mathrm{~mL}$ of distilled water and freeze dried (Christ Alpha 1-2 LDplus lyophilizer) to obtain the powder sample. The lyophilized material was weighed and transferred to a vial, kept in a refrigerator and then used. The extraction procedure was performed according to the Romanian Pharmacopoeia [26], being a standard method for obtaining plant extracts and easy to reproduce based on working parameters.

For convenience, the resulting extract was named EOT.

\subsection{Hydrogel Preparation}

In order to prepare the gel formulation, the components were used in the quantities detailed in Table 1.

Table 1. The composition of the hydrogel.

\begin{tabular}{cccccc}
\hline \multicolumn{4}{c}{ Hydrogel Base (g) } & \multicolumn{2}{c}{ Plant Extract (g) } \\
\hline Distilled water & Triethanolamine & Ethanol & Glycerin & Carbopol 940 & EOT \\
\hline 78 & 1 & 10 & 10 & 1 & 10 \\
\hline
\end{tabular}

Carbopol 940 and distilled water (1:1) $(w / w)$ were homogenized for $24 \mathrm{~h}$ for hydration, until a three-dimensional network gel was obtained. Ethanol, triethanolamine (neutralizing agent) and glycerin were added to the gel, under continuous stirring. After homogenization, the EOT was added, in a ratio of 1:9 $(w / w)$. The obtained gel formulation was characterized from the organoleptic and rheological point of view. A green-brown color and translucent appearance was noticed after homogenization, with $\mathrm{pH}=6.5$ and a viscosity coefficient of $225 \mathrm{mPa} \cdot \mathrm{s}$.

The preparation method is depicted in Figure 1.

2.3. In Vitro Evaluation of the Healing Effect of the Extract Obtained from Ocimum basilicum L. and Trifolium pratense L. (EOT)

\subsubsection{Cell Cultures}

The ability of EOT to stimulate the migration of dermal fibroblasts in vitro was assessed according to a modified scratch assay, as described in the literature [27].

Normal human dermal fibroblasts (NHDFs) along with the specific culture kit (Fibroblast Growth Medium-2 BulletKit) were purchased from Lonza Pharma \& Biotech (Basel, Switzerland). The culture medium was Dulbecco's Modified Eagle Medium containing 10\% FBS (fetal bovine serum), gentamicin $50 \mathrm{mg} / \mathrm{mL}$, amphotericin $50 \mathrm{mg} / \mathrm{mL}$ and recombinant fibroblast growth factor hFG (CC-4065) $1 \mathrm{mg} / \mathrm{mL}$. The cells were seeded in a concentration of $5 \times 10^{5}$ cells/well in 6-well plates and incubated under $5 \% \mathrm{CO}_{2}$ atmosphere at $37^{\circ} \mathrm{C}$ for three days, until approximately $85 \%$ confluency was reached. After the monolayer was formed, a straight line was scraped using a pipette tip, and the cell debris was removed by washing with PBS solution.

The EOT, prepared according to Section 2.1, was diluted at a concentration of $50 \mu \mathrm{g} / \mathrm{mL}$ in distilled water and applied to each well. The concentration $50 \mu \mathrm{g} / \mathrm{mL}$ was selected based on preliminary tests, in which different concentrations were prepared and tested $(12.5 \mu \mathrm{g} / \mathrm{mL}, 25 \mu \mathrm{g} / \mathrm{mL}$ and $50 \mu \mathrm{g} / \mathrm{mL})$, in order to evaluate a possible dose-dependent 
effect on the fibroblasts' proliferative potential (Supplementary Material S1). The plates containing untreated scratches (free fibroblast cultures) were used as a negative control (CTRL0), while allantoin, at the same concentration of $50 \mu \mathrm{g} / \mathrm{mL}$ was considered as a positive control (CTRL). The study was developed in triplicate. Therefore, the "gap" filling was monitored as a function of time (T0, T12, T24, T36, T48 and T60) and a comparison was made to the negative and positive controls. A CKX41 microscope (Olympus Inc., Tokyo, Japan) equipped with a CCD camera (DP73, Olympus Inc., Tokyo, Japan) and cellSens software was used. The recorded images were processed and statistically interpreted using an original approach described in the next section.

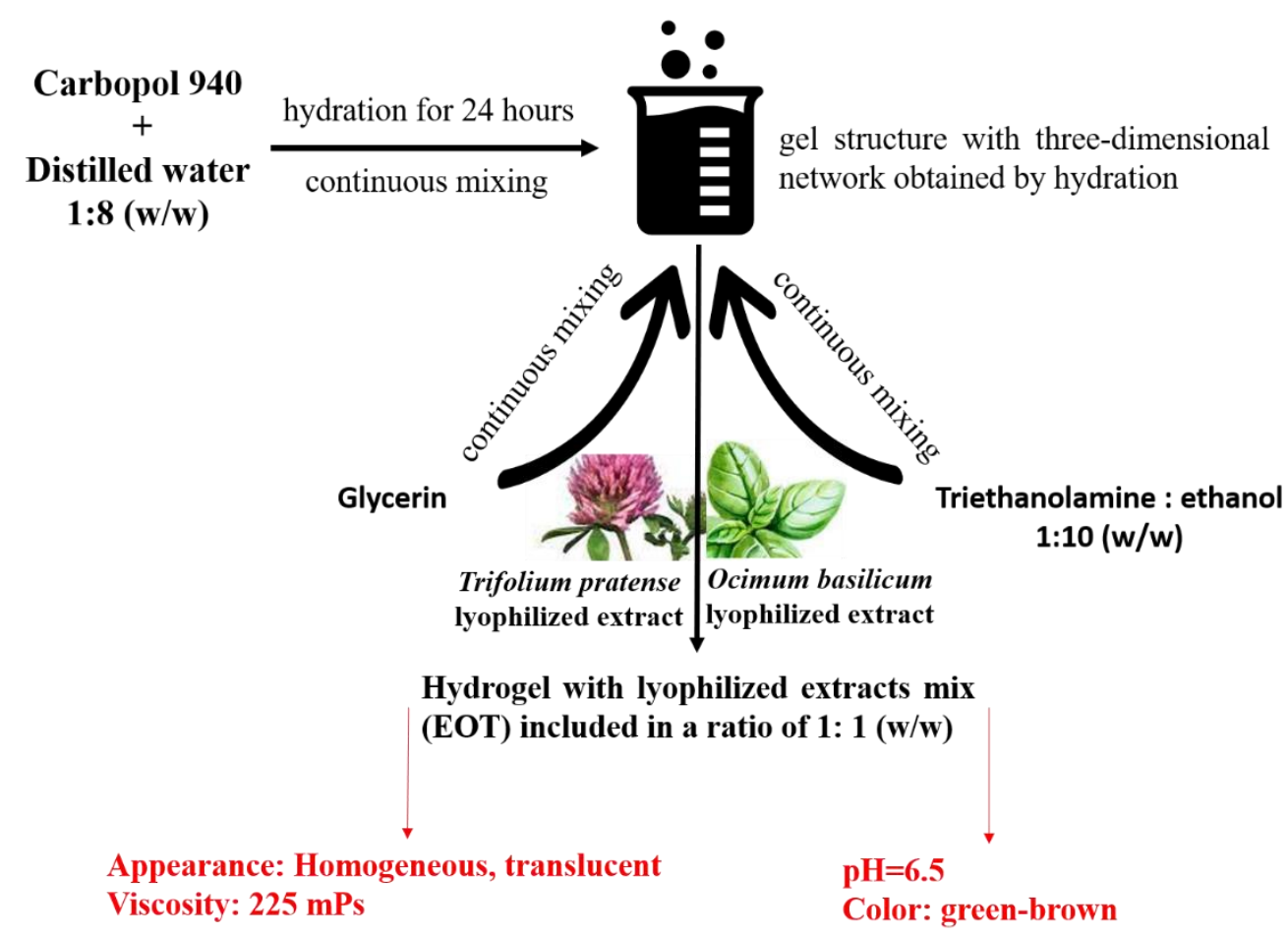

Figure 1. The preparation of gel formulation containing Trifolium pratense L. and Ocimum basilicum L. extract.

\subsubsection{Statistical Analysis}

The statistical interpretation according to the experimental design involved two statistical factors as well as the interaction factor. The first statistical factor is considered the sample, with 3 levels: C50, CTRL and CTRL0, while the second statistical factor is the time, with 6 levels: T00, T12, T24, T36, T48 and T60. The interaction factor is represented by Sample*Time with 18 levels: C50_T00, C50_T12, C50_T24, C50_T36, C50_T48, C50_T60, CTRL_T00, CTRL_T12, CTRL_T24, CTRL_T36, CTRL_T48, CTRL_T60, CTRL0_T00, CTRL0_T12, CTRL0_T24, CTRL0_T36, CTRL0_T48 and CTRL0_T60.

In order to perform quantitative comparisons of the wound closure simulation by the migration of fibroblasts, the univariate statistical analysis was carried out by two-way analysis of variance ( $2 \mathrm{w}$-ANOVA) $(p=0.05)$. Additionally, a multivariate statistical sequence was performed, consisting of: PCA (Principal Component Analysis), MANOVA (Multivariate ANOVA) and AHC (Agglomerative Hierarchical Cluster analysis). The statistical analysis and graphical representations were done using standardized statistical methods by applying MATLAB software (MathWorks Inc., Natick, MA, USA) [28].

The aim of the multivariate sequence was to validate if the C50 sample presented the optimum efficiency with respect to wound coverage in a scratch test. For this purpose, a proper number and composition of the clusters had to be established. With the appropriate sample clustering, the PCA results could be coherently interpreted. The in- 
terpretation of multivariate statistical analysis was validated by the MANOVA with a statistical significance level $p=0.05$.

The PCA method generates the principal coordinates (PC1, PC2 and PC3) of the selected parameters for all the Sample Time factor levels, by a coverage of $100 \%$ of variance. In this way, the PCA method offers an ordination multivariate statistical method that generates relative comparisons between studied samples based on their parameter values. The the variable vectors between the polar angle possessed small values, meaning that those variables were strongly correlated. In the next step, the MANOVA test was applied, so the principal coordinates (corresponding to the PC1-PC3 axis) were the numerical input for the MANOVA $(p=0.05)$ test method. The MANOVA results are presented as a matrix of statistical significance values corresponding to the pairwise sample comparisons $(p=0.05)$ and the canonical coordinates (Canon1-Canon3) of the variables for all the samples.

The analyzed quantitative parameters were: wound closure by width (Wnd_W) (\%), wound closure by area (Wnd_A) (\%) and normalized cell density (\%) inside the wound (Norm_CellDens) [27,29,30].

The assessment of wound closure by width (\%) was made for each sample at each time point, using the Formula (1):

$W n d \_W(\%) \mid$ sample at time $t=\frac{\text { Average width of wound_sample }(\mu \mathrm{m}) \text { at time } t}{\text { Average width of wound_sample }(\mu \mathrm{m}) \text { at time } t=T 00}$

For the assessment of wound closure by area (\%), the following formula was applied, for each sample at each time point (2):

$W n d \_W(\%) \mid$ sample at time $t=\frac{\text { Average area of wound_sample }\left(\mathrm{mm}^{2}\right) \text { at time } t}{\text { Average area of wound_sample }\left(\mathrm{mm}^{2}\right) \text { at time } t=T 00}$

Normalized cell density (\%) for each sample, at each time point, was calculated according to the Formula (3):

Normalized Cell Density (\%)_sample, at time $t=\frac{\text { Area of cells inside test_wound }\left(\mathrm{mm}^{2}\right) \text { at time } t}{\text { Area of cells inside test_wound }\left(\mathrm{mm}^{2}\right) \text { at time } t=\text { T00 }}$

\subsection{In Vivo Testing (Small Animal Model) of the Healing Effect of EOT-Based Hydrogel}

The hydrogel prepared according to Section 2.2. was tested in the framework of a small animal model, in accordance with the European Council Directive 2010/63/EU related to the protection of animals used for scientific purposes and Law No. 43 (11 April 2014) adopted by the Romanian Parliament on 11 April 2014. The protocol was approved by the Ethical Committee of the Faculty of Medicine and Pharmacy, University of Oradea (Reference No. 03/30.06.2021). A total of 28 Wistar rats with similar weights were selected for this experiment. The animals were housed in a controlled microclimate environment, with a dark light cycle of 12/12 h, and watering and feeding ad libitum.

A burned lesion was induced using a special device (metallic) with a diameter of $10 \mathrm{~mm}$, previously heated at $100{ }^{\circ} \mathrm{C}$ in physiological saline, and applied for $15 \mathrm{~s}$ on the surface of the shaved skin. The lesion acquired the appearance of a white ulcer evolving into a reddish lesion, due to the onset of the post-traumatic inflammatory process.

The animals were divided into 2 groups as follows: group 1 (control group, $n=7$ ) in which no treatment was applied after burning, except a sterile bandage; group 2 (study group, $\mathrm{n}=21$ ) in which the burned lesion was treated with the EOT-based hydrogel and the area was protected by a sterile bandage. A precise amount of $10 \mathrm{~g}$ of the EOT gel was used for each application and the test was performed in triplicate to ensure the reproducibility of the study.

The treatment was applied daily, during a period of 15 days, but starting at the third day, the bandage was no longer applied, as the surface crust was formed. Photographic images were recorded every 3 days, while the evolution was monitored by measuring 
the diameter of the burn. The contraction of the burned area was expressed as healing percentage, using the following formula [31,32]:

$$
\text { Healing } \%=\frac{(\text { Initial diameter of the lesion } t=0)-(\text { The diameter of the lesion at time } t)}{\text { Initial diameter of the lesion } t=0}
$$

The data were interpreted using ANOVA statistical software, and the results were considered statistically significant at values of $p<0.05$.

\subsection{Evaluation of the Effect of EOT-Based Hydrogel in a Clinical Case: Psoriasis vulgaris}

We will present the clinical case of a male patient, from the countryside, aged 68 , suffering from generalized Psoriasis vulgaris, to whom the topical treatment based on the EOT hydrogel was applied twice a day. The clinical status of the patient was assessed after one week. The study was conducted with the approval of the Institutional Ethics Committee (Decision No. CEFMF/03-30.06.2021, Research Ethics Commission of the Faculty of Medicine and Pharmacy, University of Oradea, Oradea, Romania).

\section{Results}

3.1. In Vitro Evaluation of the Wound Healing Effect: Scratch Test and Statistical Analysis

3.1.1. Univariate Analysis

The collective migration of dermal fibroblasts and the wound closure phenomenon in the presence and absence of EOT ( $50 \mu \mathrm{g} / \mathrm{mL}, \mathrm{C} 50)$, was monitored for $60 \mathrm{~h}$, as shown in Figure 2, in which the original images (column A) and computer-processed images (columns B, C and D) are presented comparatively along with the positive control CTRL (fibroblasts treated with $50 \mu \mathrm{g} / \mathrm{mL}$ allantoin) and negative control CTRL0 (treatment-free fibroblasts). The images were each captured at $12 \mathrm{~h}$ and processed at each time point, the chromatic parameters being red, green and blue, for each pixel (as exemplified in Supplementary Material S2).

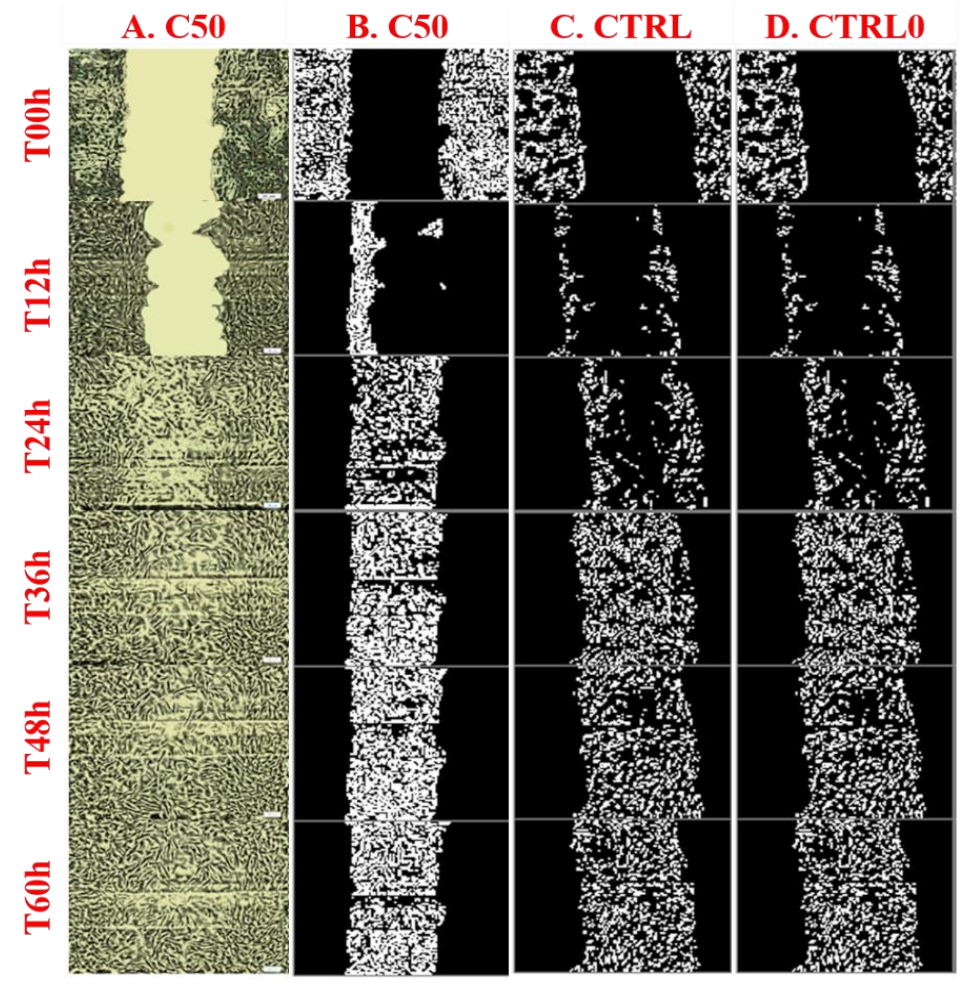

Figure 2. Spontaneous migration of dermal fibroblasts and evolution of "gap" closure in time: Column A-C50, original images of fibroblasts treated with EOT (50 $\mathrm{gg} / \mathrm{mL})$, objective 20×; Column B-C50, the same samples, after image processing; Column C-CTRL, fibroblasts treated with $50 \mu \mathrm{g} / \mathrm{mL}$ allantoin, after image processing; Column D-CTRL0, treatment-free fibroblasts. 
The univariate analysis ( $2 w$-ANOVA, $p=0.05$ ) results are presented in Figures 3-5, for each analyzed statistical factor. The selected parameters describe the collective fibroblasts' migration and the evolution of "gap" closure in time. The norm $L^{p}$ was calculated for $p=2.5$, within the definition interval $(0 ; 1)$; the maximum $L^{p}$ value indicates the optimum behavior with respect to the analyzed parameters. The details of the computational analysis and the exact values of the norm $L^{p}$ calculated for $p=2.5$, within the definition interval $(0 ; 1)$, are presented as Supplementary Material S2.

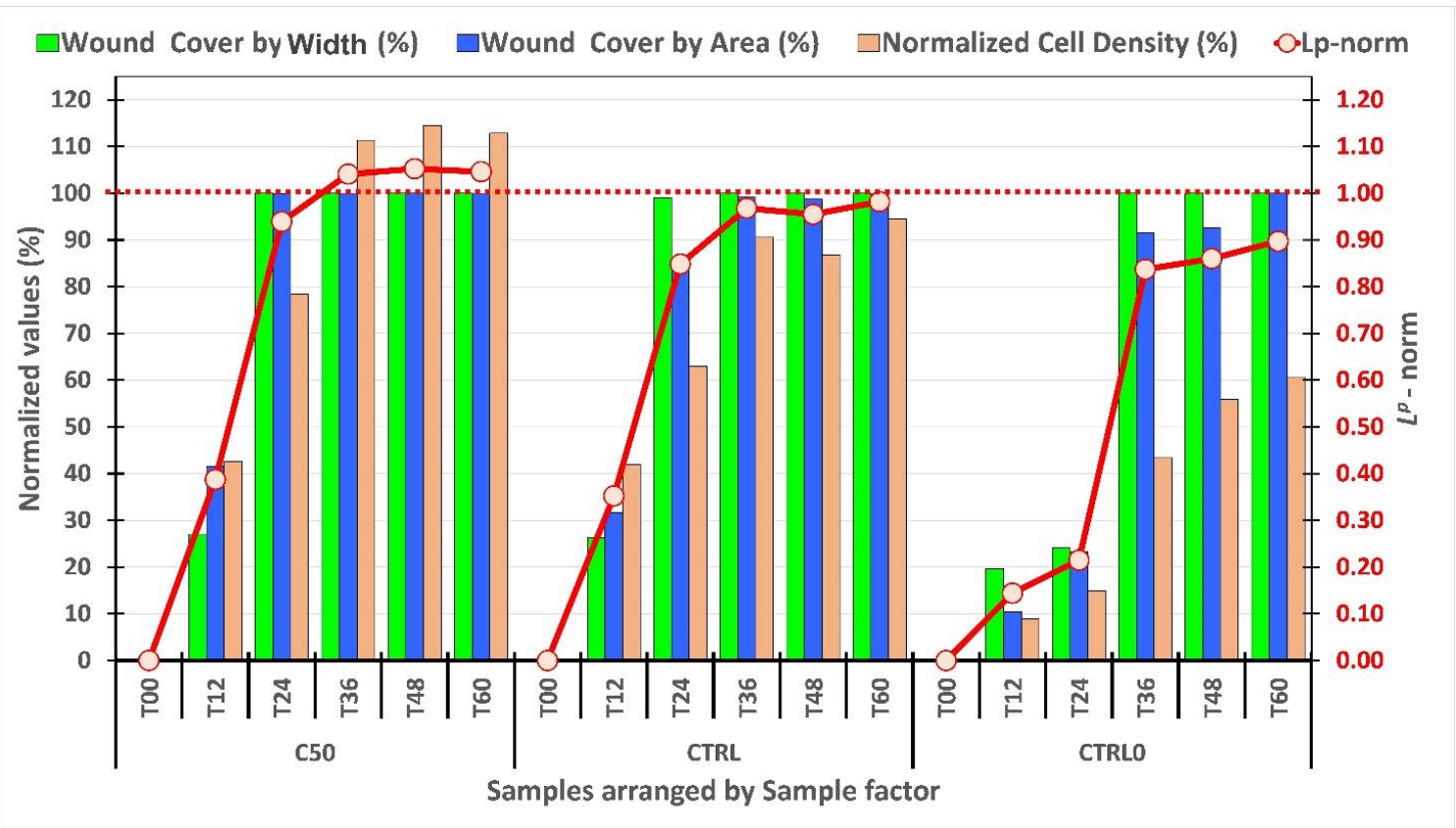

Figure 3. Evolution of the migration of fibroblasts and "gap coverage" (which is similar to wound closure), with respect to the statistical factor "Sample" (average values). The quantitative parameters were: wound closure by width, wound closure by area and normalized cell density inside the wound.

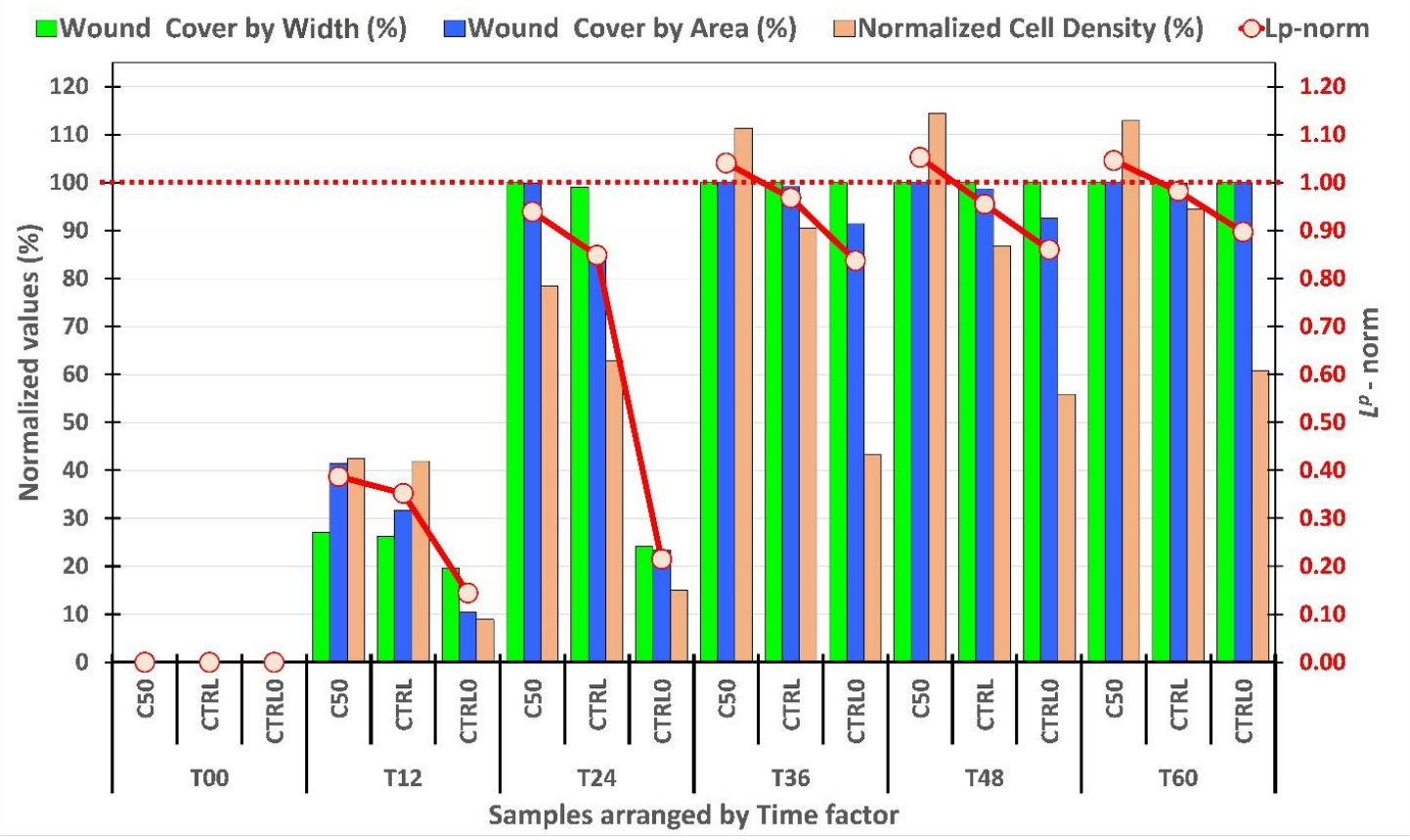

Figure 4. Evolution of the migration of fibroblasts and "gap coverage" with respect to statistical factor "Time" (average values). The quantitative parameters were: wound closure by width, wound closure by area and normalized cell density inside the wound. 


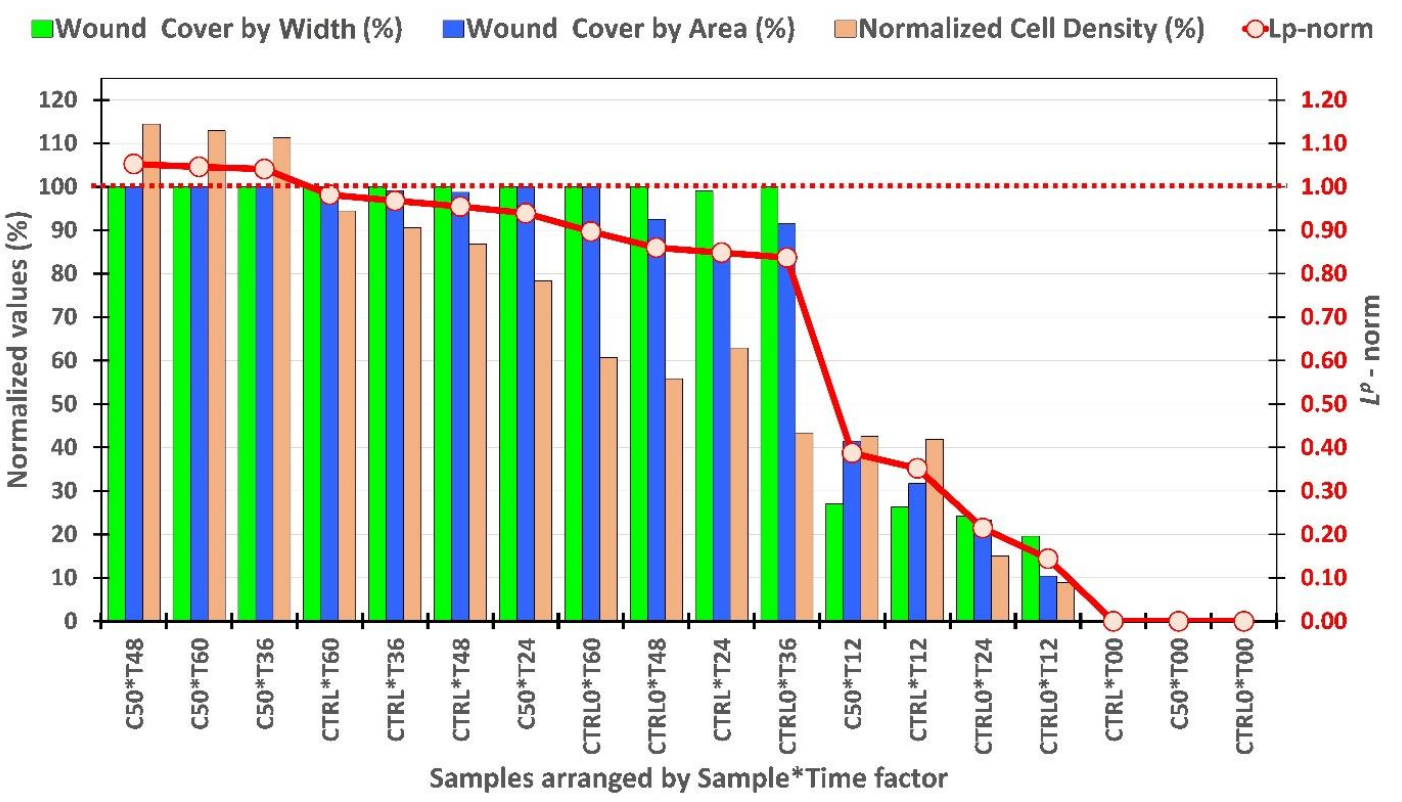

Figure 5. Evolution of the migration of fibroblasts and "gap coverage" with respect to statistical factor "Sample*Time" (average values). The quantitative parameters were: wound closure by width, wound closure by area and normalized cell density inside the wound.

According to Figure 3, it can be observed that the values of the $L^{p}$ norm are in ascending order from T00 to T60, which demonstrates that the phenomenon of collective migration and wound closure is achieved in all samples, without anomalies. At any point in time, the sample C50 presents the best values in terms of wound closure. Moreover, at the specific time points T36, T48 and T60, the value of $L^{p}>1$ denotes a monolayer recovery with higher density compared to the initial one. A similar behavior can be seen in Figure 4, in which the C50 sample shows $L^{p}>1$ at T36, T48 and T60, denoting the fastest recovery process when compared to CTRL and CTRL0. In Figure 5, the results are organized by Sample*Time factor, so the average values are calculated for each sample at each time point. The corresponding values of $L^{p}$ norm are in ascending order, following a monotonous feature, with several slopes, which denote different particularities of the fibroblasts' collective migration and wound closure process. Similar to the previous results, the samples C50*T36, C50*T48 and C50*T60 exhibit supra-unitary values of the $L^{p}$ norm.

By corroborating the above results, it can be stated that the application of the $L^{p}$ norm to the analyzed parameters is useful in discriminating the samples with the fastest and most effective coverage processes.

\subsubsection{Multivariate Statistical Analysis and Hierarchical Cluster Analysis}

A combined PCA (Principal Component Analysis)-MANOVA $(p=0.05)$ multivariate statistical sequence and HCA (Hierarchical Cluster Analysis) were applied in order to obtain statistical confidence in the results.

Two-dimensional and three-dimensional PCA biplots (Figure 6) display the variable vectors, starting from the origin of the principal coordinates system, and pointing out the direction of the highest abundance or concentration values.

The biplots in the original PCA coordinates of the MANOVA and AHC results with clusters are presented in Figure 7, in order to obtain the proper number of clusters, based on the MANOVA's $p$-values matrix. More details and specific parameters of this method are presented as Supplementary Material S3, including the AHC results presented as a heat map with a dendrogram, in order to obtain the proper number of clusters, based on the MANOVA's $p$-values matrix. 
The sample clusters associated with the fibroblasts' collective migration and wound closure were characterized in a multivariate way. Cluster \#9 (C50_T36, C50_T48 and C50_T60) presents the highest level of normalized cell density (Norm_CellDens), including inside the wound cell coverage area (inWnd_CellA), while Cluster \#6 (C50_T12 and CTRL_T12) presents an average level of normalized cell density (Norm_CellDens), including inside the wound cell coverage area (inWnd_CellA). The rest of the associated clusters present lower levels of the selected parameters. In conclusion, the C50 sample overcomes the CTRL and CTRL0 samples at time factor levels of 12, 36, and $48 \mathrm{~h}$. Hence, it can be stated that this concentration is suitable for further biomedical applications.

A

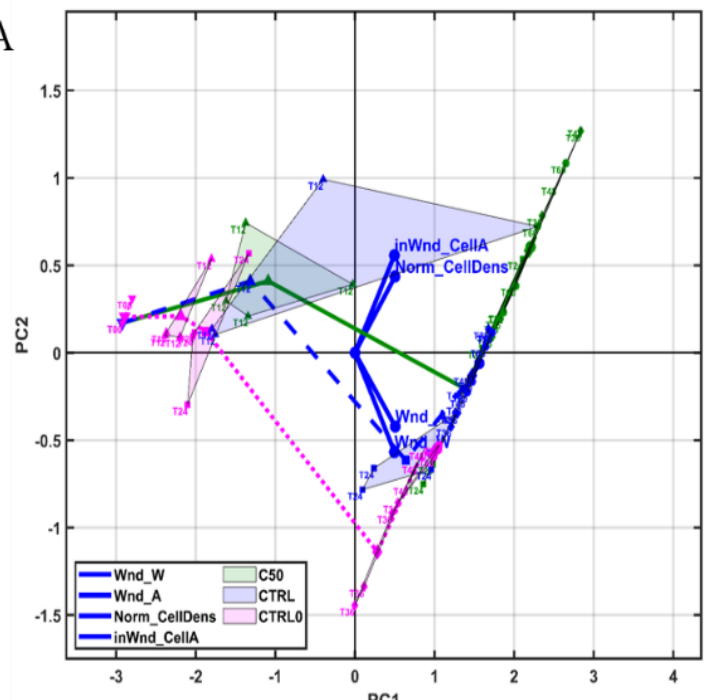

B

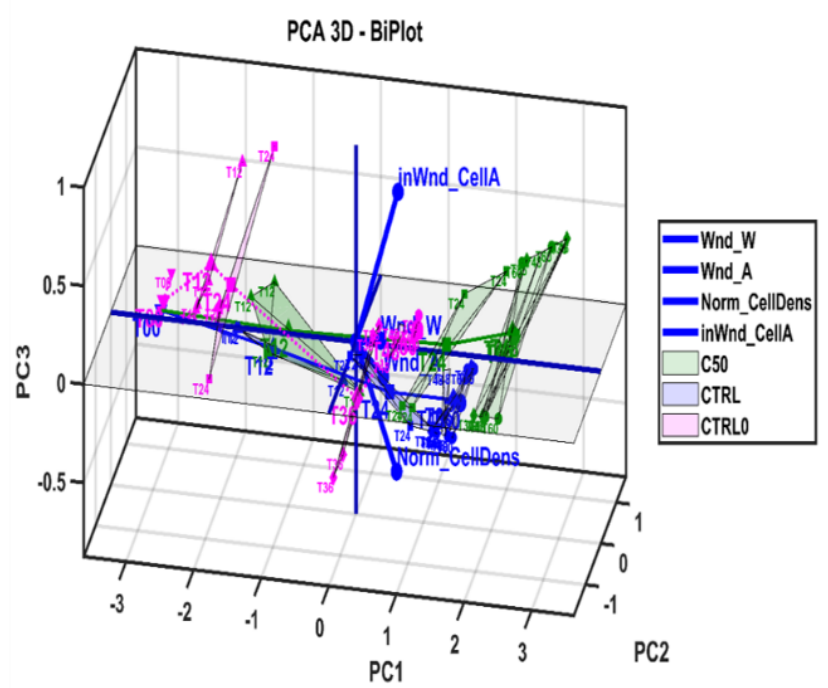

Figure 6. Biplots of PCA results: (A) 2D representation for PC1 and PC2 principal components; (B) 3D representation for PC1, PC2 and PC3 principal components. All sample values were involved in PCA calculus.
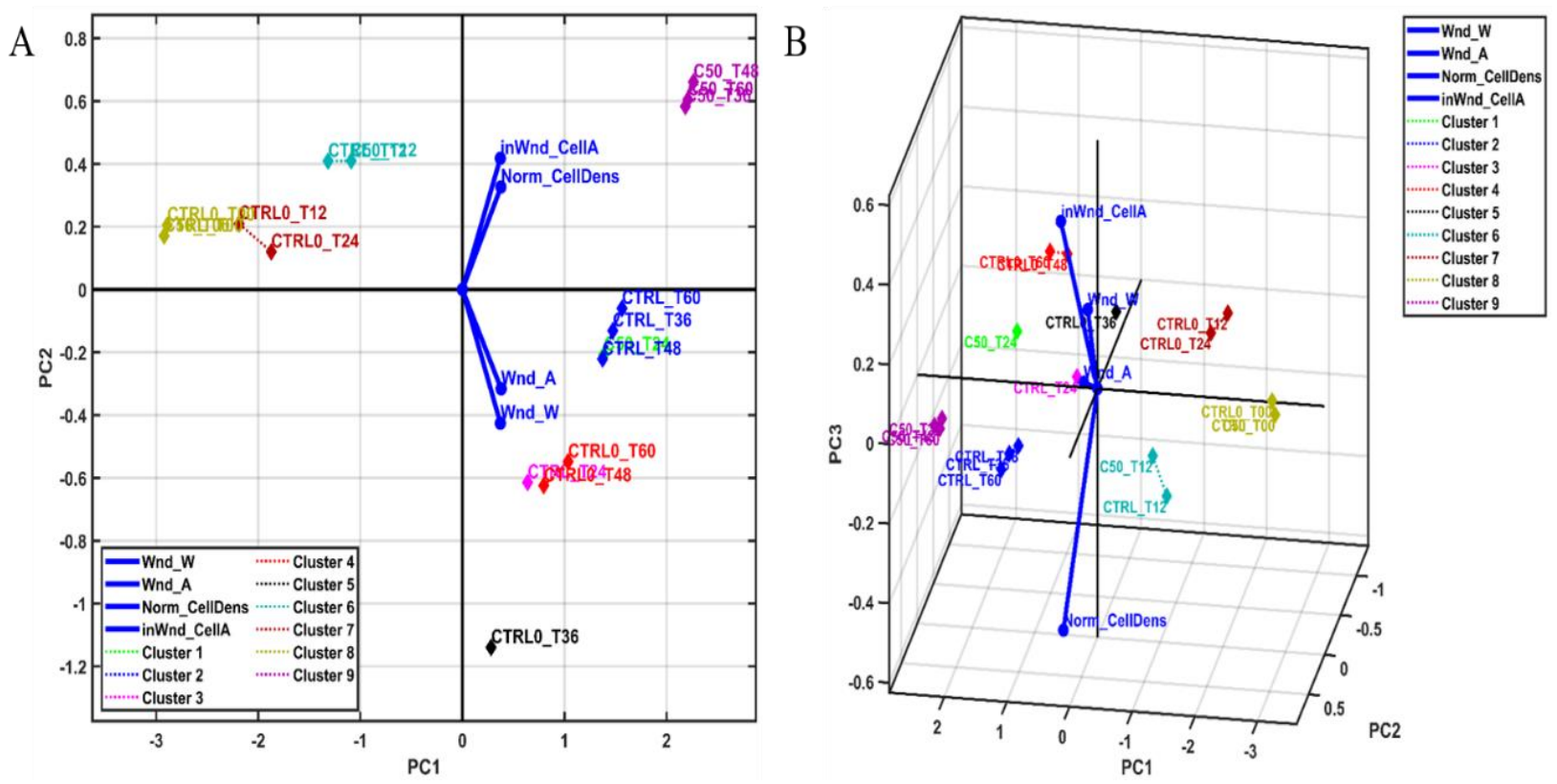

Figure 7. Biplots in original PCA coordinates of MANOVA and AHC results with clusters: (A) 2D representation for PC1 and PC2 principal components; (B) 3D representation for PC1, PC2 and PC3 principal components. 


\subsection{In Vivo Evaluation of the Healing Effect of EOT Extract: Small Animal Model}

Since the in vitro results were favorable and promising, in vivo tests were performed using EOT incorporated into a novel hydrogel formulation.

The hydrogel formulation based on EOT presents characteristic properties such as homogeneity and $\mathrm{pH}$ and viscosity values that correspond to quality standards [18], making it suitable for topical applications.

The evolution of the wound created by burning the superficial tissue is presented in Figure 8, showing a good local tolerance of the hydrogel formulation. The results confirm the faster healing of the study groups to which the novel formulation was applied, compared to the control group.

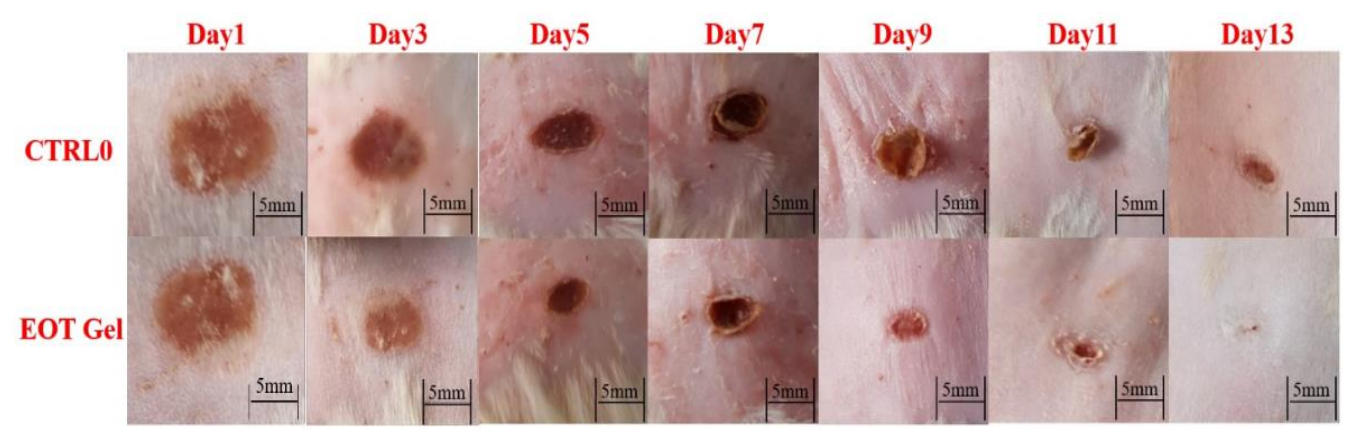

Figure 8. Evolution in time (contraction) of the wound healing process in both groups (the control group and the EOT hydrogel-treated group).

The contraction of the wounded area is expressed as the diameter of the lesion measured every two days, as presented in Table 2.

Table 2. Evolution of the induced lesion expressed as the diameter of the lesion measured every 2 days in both groups, along with the statistical interpretation (average value \pm SD). The results were considered statistically significant at values of $p<0.05$.

\begin{tabular}{cccccccc}
\hline & $\begin{array}{c}\text { Day 1 } \\
(\mathbf{m m})\end{array}$ & $\begin{array}{c}\text { Day 3 } \\
(\mathbf{m m})\end{array}$ & $\begin{array}{c}\text { Day 5 } \\
(\mathbf{m m})\end{array}$ & $\begin{array}{c}\text { Day 7 } \\
(\mathbf{m m})\end{array}$ & $\begin{array}{c}\text { Day 9 } \\
\mathbf{( m m})\end{array}$ & $\begin{array}{c}\text { Day 11 } \\
(\mathbf{m m})\end{array}$ & $\begin{array}{c}\text { Day 13 } \\
(\mathbf{m m})\end{array}$ \\
\hline EOT Gel & $10.2 \pm 0.2$ & $8.7 \pm 0.4$ & $6.5 \pm 0.7$ & $6.3 \pm 0.7$ & $4.1 \pm 0.3$ & $1.8 \pm 0.4$ & $0.5 \pm 0.05$ \\
\hline CTRL0 & $10.5 \pm 0.1$ & $9.8 \pm 0.6$ & $8.2 \pm 0.5$ & $7.1 \pm 0.6$ & $6.2 \pm 0.5$ & $3.5 \pm 0.5$ & $2.0 \pm 0.2$ \\
\hline $\begin{array}{c}\text { CTRL0 vs. } \\
\text { EOT Gel }\end{array}$ & $p>0.05$ & $p<0.05$ & $p<0.05$ & $p<0.05$ & $p>0.05$ & $p<0.01$ & $p<0.05$ \\
\hline
\end{tabular}

Therefore, after analyzing the evolution of the induced lesion and the statistical interpretation, the percentage of wound healing using EOT gel compared to CTRL0 as a function of time (Figure 9) was calculated using Equation (4), which indicates that the healing process is faster in the case of the study sample compared to the control, regardless of the time.

\subsection{In Vivo Evaluation of the Effect of EOT-Based Hydrogel in a Case of Psoriasis vulgaris}

We will present the clinical case of a male patient, from the countryside, aged 68 , suffering from generalized Psoriasis vulgaris, for which he was using only local treatment during flare-ups. The patient came to our clinic presenting well-defined erythrodermic plaques covered with silvery-white scales on his superior and inferior extremities and trunk. The patient was not under any treatment.

The classic red and purple areas of dry, scaly and sometimes itchy skin, with good laboratory data, allowed us to establish the diagnosis of Psoriasis vulgaris, but we also performed a punch biopsy to confirm our diagnosis. We initiated local treatment with EOT-based hydrogel twice a day, in the morning and evening. 


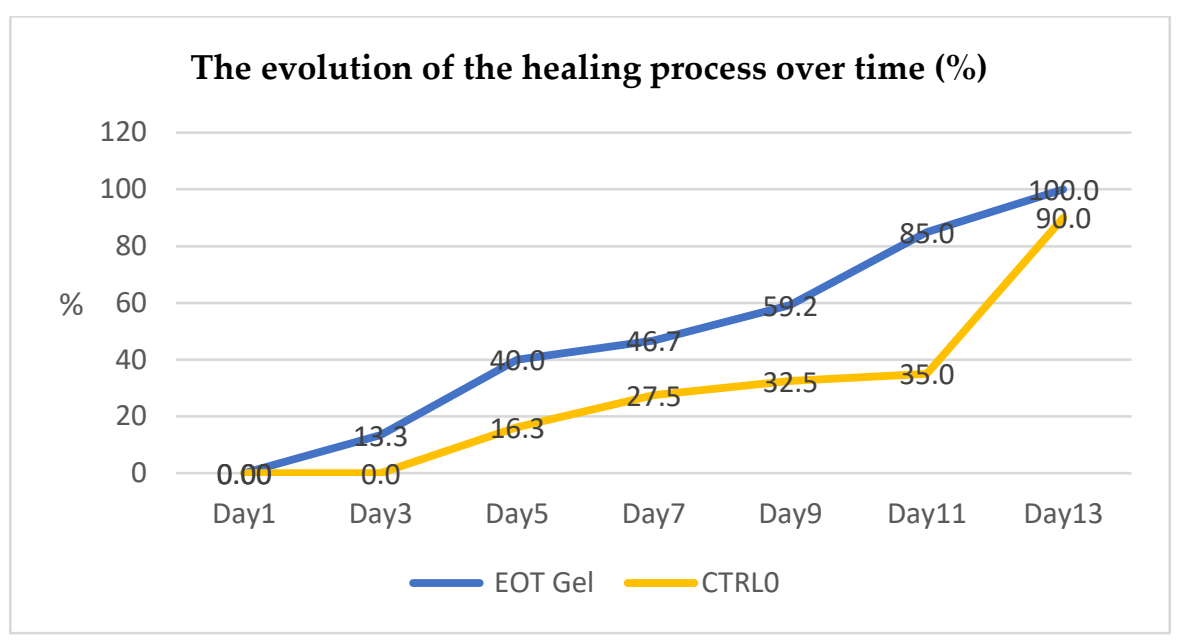

Figure 9. Evolution of the wound healing process in the case of EOT gel compared to control (CTRL0 - no treatment) as a function of time, expressed as a percentage (\%).

The patient was reviewed in our outpatient service after one week and his erythrodermic plaques were visibly diminished with the silvery-white, fine scales reduced.

Additionally, the patient stopped complaining of itchy skin, and it is important to mention that his psychological status was also improved by the remission of his skin lesions (Figure 10).

Before treatment

After one week of EOT gel treatment

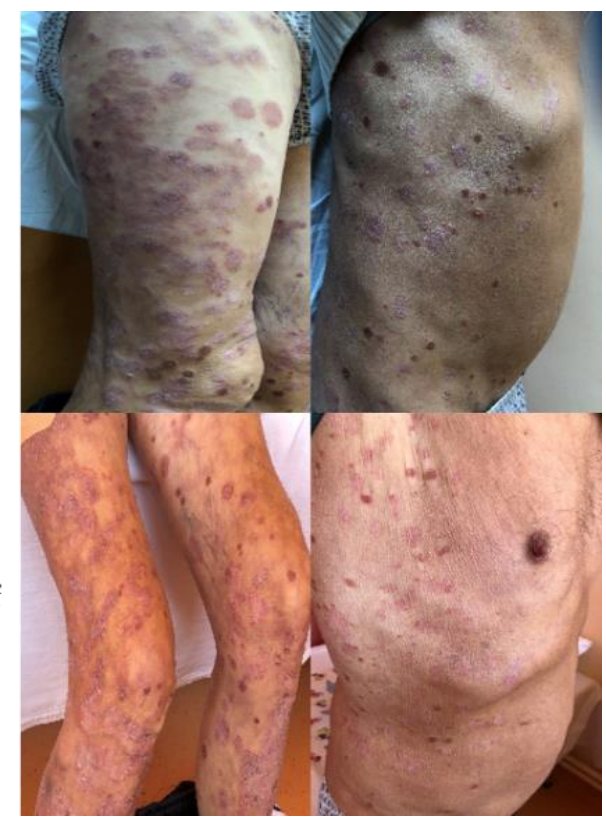

Figure 10. Clinical aspects of Psoriasis vulgaris treated with gel formulation of Ocimum basilicum and Trifolium pratense extract mixture.

\section{Discussion}

A comparative phytochemical and antioxidative capacity characterization of Trifolium pratense L. and Ocimum basilicum L. has been previously reported by our group [7]. The HPLC-UV method was applied for the identification and quantification of the polyphenols. O. basilicum extract was found to be the richest in ferulic acid, while T. pratense extract presented higher concentrations of other active principles, especially chlorogenic acid. The highest total phenolic and flavonoid contents were found in O. basilicum, highlighting its strong antioxidant activity, as measured by the DPPH, FRAP and CUPRAC 
methods. These results indicated that these two species could be valuable natural sources of antioxidants with therapeutic potential.

Recently, we also pointed out the potential combined effects of the mixed extract (T. pratense and O. basilicum) in terms of applications for wound healing, based on the common bioactive compounds identified in their composition, along with their similar therapeutic activities [12]. Thus, the present work was based on the hypothesis that an extract containing a mixture of both plants might work synergistically with great benefits for wound healing processes.

The healing effects of the extracts from Ocimum sp. and Trifolium sp. have been separately tested by other authors, obtaining very good results [5,9]. In our study, the extract obtained by combining both plants (EOT) demonstrated a proliferative healing effect exerted on human dermal fibroblasts, which was proved to be much stronger than previously reported results, at a lower concentration $(50 \mu \mathrm{g} / \mathrm{mL})$, showing a synergistic effect of the combined plants. The result was acquired in the framework of an elaborated study, including a conventional scratch test and a very complex statistical interpretation. Multiple quantification methods were used to assess collective cell migration in a scratch assay. Univariate and multivariate statistical analysis combined with Hierarchical Cluster Analysis were performed as an original approach. Image processing was also performed for each sample, and was compared to the positive and negative controls at each time point (T00, T12, T24, T36, T48 and T60).

It was observed that both the practical and theoretical methods (the choice of parameters) are adequate and very accurate. Based on an in vitro test and statistical analysis, we demonstrated that the sample C50 overcomes CTRL and CTRL0 samples at the time points of 12,36 and $48 \mathrm{~h}$. By using the Hierarchical Cluster Analysis and cluster evolution in time, we can state that the sample C50 presents the best healing efficiency, in terms of time necessary for complete healing and also in terms of the recovery of the fibroblasts' density.

As the next step of the study, a novel hydrogel formulation was created, based on EOT. Hydrogels, unlike other topical formulas, have a great advantage in the wound healing process [33], as they function as a hydrocolloid dressing with the ability to maintain local moisture while gradually releasing the compounds included in the three-dimensional network [34]. The major advantages of this formula (and the reasons why it was chosen for incorporation with EOT) are its long-term, controlled release capacity and the possibility to adjust the properties of the hydrogel in order to accelerate the healing of existing wounds $[31,33,35]$. The use of Carbopol has proven to be beneficial, according to the literature, as it improves the wound healing process due to its ability to gradually release the compounds included in the gel network and the promotion of oxygen penetration into the wound $[33,36,37]$. Hydrogel incorporated with EOT was expected to possess anti-inflammatory, antimicrobial and antioxidant properties $[31,37,38]$. The antioxidant capacity of the formulated hydrogel is due to the chemical composition of EOT, being rich in phenols, flavonoids, volatile oils, etc. [5,25,39].

According to the literature, hydrogel formulations present other advantages such as flexibility and biocompatibility, and the ability to maintain low wound temperature and high-water content, calming the wound area [37]. Moreover, hydrogels have a cooling and pain-relieving effect. Hydrogels are suitable regardless of the stage of the wound healing process (hemostasis, inflammation, migration/cell proliferation and maturation) and, being non-irritating, they are suitable for a wide range of dermal diseases $[37,40]$.

To date, in vivo studies have been performed in rats, in order to test the healing effect of Ocimum sp. extract [31]; however, no such studies have been performed for Trifolium sp. extract. According to the study completed by Ali Khan et al. for the Ocimum sp. extract, regarding the wound healing process as a function of time, the results did not differ statistically from the control [31]. However, the authors state that the healing process took place due to the complex chemical composition of Ocimum basilicum extract and because it has the ability to stimulate angiogenesis in the wound. The authors stated that the highest percentage $(90 \%)$ of wound healing occurred on day 16 [31]. 
By comparing our study with previous in vivo results reported in the literature, we can affirm that the EOT hydrogel tested in our study possesses superior healing properties, as the wound healing was proved to reach $100 \%$ on day 13 , which is significantly faster than the reported single extract. Our results could be explained as the synergic effect of the combined compounds resulting from the plant mixture.

We also consider that the favorable results obtained in vivo are not only due to the synergy of the two extracts used in the EOT gel formula but also due to the body's immune response. Thus, the final response (scarring of the lesion produced by the burn) represents the corroboration of the two factors: the immune response and the applied EOT gel.

It is well known that the wound healing process comprises three important stages. In the first phase, vasoconstriction and blood coagulation take place, leading to the debridement of the wound with the help of phagocytic cells at that level [4]. The second phase is the most important stage because fibroblast cells are involved in the process of proliferation and migration, along with the consolidation of collagen fibers and the angiogenesis process. The last stage is remodeling and re-epithelialization, when practically, the dermis regains its elasticity and initial appearance [5].

According to the literature, fibroblast growth factor 18 (FGF18) and vascular endothelial growth factor A (VEGFA) both possess a key role in the wound healing process [41]. It is understood that high concentrations of growth factors stimulate fibroblast proliferation, while low concentrations promote cell migration. The cell's decision to migrate or proliferate therefore depends on the level of cell growth factor [41].

In our study, the application of EOT was shown to have an influence on both the migration and proliferation of fibroblasts, as the as the immune process and the level of growth factor is involved. The explanation for this is based on the observation that, in the first $24 \mathrm{~h}$, the migration of fibroblasts was observed (the hypothesis being that the growth factor was present in low concentrations), while in the next 24-36 h, cell proliferation was observed (the hypothesis being that the growth factor was present in high concentrations).

Moreover, there are several data in the literature supporting our results by evidencing that the active compounds found in our extract (such as polyphenols, flavonoids and volatile oils) are involved in the stimulation of immune processes, demonstrating antiinflammatory, antimicrobial and antioxidant activity [12]. Hence, by corroborating the in vitro and in vivo results, we consider that the wound healing response after 13 days of treatment with the EOT gel is actually a summation of the EOT's effect (due to its bioactive compounds) and the body's immune response.

Additionally, the efficiency of EOT-based gel was demonstrated in a clinical case of Psoriasis vulgaris. We emphasize that by treating the patient with EOT-based hydrogel we can avoid using local corticosteroids, meaning that we can avoid their side effects, which over time can lead to aggravated types of Psoriasis vulgaris like pustular psoriasis or erythrodermic psoriasis. Psoriasis is an inflammatory skin disease that has characteristic epidermal alterations caused by the keratinocyte hyperproliferation, similar to untreated wounds. Keratinocyte hyperproliferation is also accompanied by abnormal cell differentiation. Psoriasis is a multifactorial disease that has polygenic influences and affects skin and joints. It is also a common disease, affecting 2-3\% of many populations. Even if the pathophysiology remains unknown, several studies indicate that immune dysfunction might be an important trigger. Like other multifactorial pathologies, clinical manifestations of psoriasis differ widely. The most common type of psoriasis is plaque psoriasis, where sharp lesions appear on previously normal skin. Histopathology of psoriasis lesions show that besides inflammation, there are specific alterations such as keratinocyte hyperproliferation and abnormal cell differentiation [42].

Our clinical case's status was reevaluated after one week. The patient applied EOTbased hydrogel twice a day and improvements were noticed such as reduced erythrodermic plaques, less silvery-white scales and less pruritus. The patient did not mention any side effects after the treatment with EOT-based hydrogel. 


\section{Conclusions}

In the context of an ongoing interest in replacing synthetic compounds with natural ones in order to develop novel therapeutical formulations, the aim of our work was to demonstrate the wound healing effect of mixed Ocimum basilicum and Trifolium pratense extract (EOT) by in vitro and in vivo study. Based on an in vitro test (scratch test) combined with an original approach of statistical analysis, we demonstrated that a concentration of $50 \mu \mathrm{g} / \mathrm{mL}$ of EOT was enough to obtain a very good healing effect, in terms of time necessary for complete coverage and also in terms of recovery of the fibroblast density. In the animal model, a novel hydrogel formulation prepared based on EOT demonstrated complete wound healing (100\%) after 13 days.

Moreover, the efficiency of EOT-based gel was demonstrated in a clinical case of Psoriasis vulgaris, showing the diminution of the characteristic erythema after one week of treatment. Within the limitations of the present study, we conclude that the efficiency of the novel hydrogel formulation could be explained as the synergic effect of the bioactive compounds from the plant mixture, combined with the body's immune response. In our future work, our goal will be to investigate the long-term effects of EOT hydrogel treatment (to highlight the effects of the hydrogel after its withdrawal from the wound) including possible toxic effects, analyzing the biochemical markers and immune components, along with other possible applications in different acute and chronic diseases.

Supplementary Materials: The following are available online at https://www.mdpi.com/article/ 10.3390/pr9112096/s1, Supplementary material S1: Results of the preliminary in vitro tests using different EOT concentrations ( $12.5 \mu \mathrm{g} / \mathrm{mL}, 25 \mu \mathrm{g} / \mathrm{mL}, 50 \mu \mathrm{g} / \mathrm{mL})$, Supplementary material S2: The details of the computational analysis and the exact values of the norm $L^{p}$ calculated for $p=2.5$, within the definition interval [0; 1], Supplementary material S3: Multivariate Statistical Analysis and Hierarchical Cluster Analysis parameters.

Author Contributions: Conceptualization, A.A. and S.C.; methodology, S.I.V.; software, A.C.T.; validation, L.V., M.Z. (Mihaela Zdrîncă) and M.Z. (Marcel Zdrîncă); formal analysis, L.F.; investigation, I.B. and I.A.A.; resources, A.A.; data curation, A.A. and I.A.A.; writing - original draft preparation, F.M.; writing - review and editing, L.F.; visualization, I.B.; supervision, S.C.; project administration, M.D. and A.A. All authors have read and agreed to the published version of the manuscript.

Funding: This research received no external funding.

Institutional Review Board Statement: The study was conducted according to the guidelines of the Declaration of Helsinki, and approved by the Institutional Review Board (or Ethics Committee) of the University of Oradea, Faculty of Medicine and Pharmacy (protocol code CEFMF/03, date of approval 30 June 2021).

Informed Consent Statement: The Patient Consent Form for Articles Containing Patient Details and/or Images was submitted along with the manuscript.

Data Availability Statement: Data are available from the corresponding author upon reasonable request.

Conflicts of Interest: The authors declare no conflict of interest.

\section{References}

1. Pazyar, N.; Yaghoobi, R.; Rafiee, E.; Mehrabian, A.; Feily, A. Skin Wound Healing and Phytomedicine: A Review. Ski. Pharmacol. Physiol. 2014, 27, 303-310. [CrossRef]

2. Freiesleben, S.H.; Soelberg, J.; Nyberg, N.T.; Jäger, A.K. Determination of the Wound Healing Potentials of Medicinal Plants Historically Used in Ghana. Evid.-Based Complement. Alternat. Med. 2017, 2017, 9480791. [CrossRef] [PubMed]

3. Qureshi, M.; Khatoon, F.; Ahmed, S. An Overview on Wounds Their Issues and Natural Remedies for Wound Healing. Biochem. Physiol. 2015, 4. [CrossRef]

4. WHO I Global Status Report on Noncommunicable Diseases. 2014. Available online: http:/ / www.who.int/nmh/publications / ncd-status-report-2014/en/ (accessed on 31 May 2021).

5. Dhama, K.; Sharun, K.; Gugjoo, M.B.; Tiwari, R.; Alagawany, M.; Yatoo, M.I.; Thakur, P.; Iqbal, H.M.N.; Chaicumpa, W.; Michalak, I.; et al. A Comprehensive Review on Chemical Profile and Pharmacological Activities of Ocimum Basilicum. Food Rev. Int. 2021, 1-29. [CrossRef] 
6. Kolodziejczyk-Czepas, J. Trifolium Species-Derived Substances and Extracts-Biological Activity and Prospects for Medicinal Applications. J. Ethnopharmacol. 2012, 143, 14-23. [CrossRef]

7. Antonescu, A.I.; Jurca, T.; Gligor, F.; Craciun, I.; Fritea, L.; Patay, E.B.; Muresan, M.; Udeanu, D.I.; Ionita, C.A.; Antonescu, A.; et al. Comparative Phytochemical and Antioxidative Characterization of Trifolium pratense L. and Ocimum basilicum L. Farmacia 2019, 67, 146-153. [CrossRef]

8. Kwee, E.M.; Niemeyer, E.D. Variations in Phenolic Composition and Antioxidant Properties among 15 Basil (Ocimum basilicum L.) Cultivars. Food Chem. 2011, 128, 1044-1050. [CrossRef]

9. Vlaisavljevic, S.; Kaurinovic, B.; Popovic, M.; Djurendic-Brenesel, M.; Vasiljevic, B.; Cvetkovic, D.; Vasiljevic, S. Trifolium pratense L. as a Potential Natural Antioxidant. Molecules 2014, 19, 713-725. [CrossRef]

10. Złotek, U.; Michalak-Majewska, M.; Szymanowska, U. Effect of Jasmonic Acid Elicitation on the Yield, Chemical Composition, and Antioxidant and Anti-Inflammatory Properties of Essential Oil of Lettuce Leaf Basil (Ocimum basilicum L.). Food Chem. 2016, 213, 1-7. [CrossRef]

11. Akbaribazm, M.; Khazaei, M.R.; Khazaei, M. Trifolium pratense L. (Red Clover) Extract and Doxorubicin Synergistically Inhibits Proliferation of 4T1 Breast Cancer in Tumor-Bearing BALB/c Mice through Modulation of Apoptosis and Increase Antioxidant and Anti-Inflammatory Related Pathways. Food Sci. Nutr. 2020, 8, 4276-4290. [CrossRef]

12. Antonescu Mintas, A.-I.; Miere Groza, F.; Fritea, L.; Ganea, M.; Zdrinca, M.; Dobjanschi, L.; Antonescu, A.; Vicas, S.I.; Bodog, F.; Sindhu, R.K.; et al. Perspectives on the Combined Effects of Ocimum Basilicum and Trifolium Pratense Extracts in Terms of Phytochemical Profile and Pharmacological Effects. Plants 2021, 10, 1390. [CrossRef]

13. Wu, Z.; Xu, B.; Yu, Z.; He, Q.; Hu, Z.; Zhou, S.; Chen, M.; Zhu, L. Trifolium Flavonoids Overcome Gefitinib Resistance of Non-Small-Cell Lung Cancer Cell by Suppressing ERK and STAT3 Signaling Pathways. Biomed. Res. Int. 2020, $2020,2491304$. [CrossRef]

14. Sakkas, H.; Papadopoulou, C. Antimicrobial Activity of Basil, Oregano, and Thyme Essential Oils. J. Microbiol. Biotechnol. 2017, 27, 429-438. [CrossRef] [PubMed]

15. Harlow, B.E.; Flythe, M.D.; Kagan, I.A.; Goodman, J.P.; Klotz, J.L.; Aiken, G.E. Isoflavone Supplementation, via Red Clover Hay, Alters the Rumen Microbial Community and Promotes Weight Gain of Steers Grazing Mixed Grass Pastures. PLoS ONE 2020, 15, e0229200. [CrossRef]

16. Mediratta, P.K.; Sharma, K.K.; Singh, S. Evaluation of Immunomodulatory Potential of Ocimum Sanctum Seed Oil and Its Possible Mechanism of Action. J. Ethnopharmacol. 2002, 80, 15-20. [CrossRef]

17. Okoye, F.B.; Obonga, W.O.; Onyegbule, F.A.; Ndu, O.O.; Ihekwereme, C.P. Chemical composition and anti-inflammatory activity of essential oils from the leaves of Ocimum basilicum L. and Ocimum gratissimum L. (Lamiaceae). Int. J. Pharm. Sci. Res. 2014, 5, 2174-2180.

18. Takeuchi, H.; Takahashi-Muto, C.; Nagase, M.; Kassai, M.; Tanaka-Yachi, R.; Kiyose, C. Anti-Inflammatory Effects of Extracts of Sweet Basil (Ocimum basilicum L.) on a Co-Culture of 3T3-L1 Adipocytes and RAW264.7 Macrophages. J. Oleo Sci. 2020, 69, 487-493. [CrossRef]

19. Dhaliwal, K.; Lopez, N. Hydrogel Dressings and Their Application in Burn Wound Care. Br. J. Community Nurs. 2018, 23, S24-S27. [CrossRef]

20. Tavakoli, S.; Klar, A.S. Advanced Hydrogels as Wound Dressings. Biomolecules 2020, 10, 1169. [CrossRef]

21. Rüther, L.; Voss, W. Hydrogel or Ointment? Comparison of Five Different Galenics Regarding Tissue Breathability and Transepidermal Water Loss. Heliyon 2021, 7, e06071. [CrossRef]

22. Korting, H.; Schöllmann, C.; White, R. Management of Minor Acute Cutaneous Wounds: Importance of Wound Healing in a Moist Environment. J. Eur. Acad. Dermatol. Venereol. JEADV 2011, 25, 130-137. [CrossRef] [PubMed]

23. Koehler, J.; Brandl, F.; Goepferich, A. Hydrogel Wound Dressings for Bioactive Treatment of Acute and Chronic Wounds. Eur. Polym. J. 2018, 100. [CrossRef]

24. Eyerich, K.; Eyerich, S. Immune Response Patterns in Non-Communicable Inflammatory Skin Diseases. J. Eur. Acad. Dermatol. Venereol. 2018, 32, 692-703. [CrossRef]

25. Miere (Groza), F.; Vicas, S.I.; Timar, A.V.; Ganea, M.; Zdrinca, M.; Cavalu, S.; Fritea, L.; Vicas, L.; Muresan, M.; Pallag, A.; et al. Preparation and Characterization of Two Different Liposomal Formulations with Bioactive Natural Extract for Multiple Applications. Processes 2021, 9, 432. [CrossRef]

26. Farmacopeea Romana-Editia a X-a. Available online: https://www.ed-medicala.ro/189-farmacopeea-romana-editia-a-X-a.html (accessed on 9 November 2021).

27. Belkacemi, A.; Laschke, M.W.; Menger, M.D.; Flockerzi, V. Scratch Migration Assay and Dorsal Skinfold Chamber for In Vitro and In Vivo Analysis of Wound Healing. J. Vis. Exp. 2019. [CrossRef] [PubMed]

28. Bobadilla, A.V.P.; Arévalo, J.; Sarró, E.; Byrne, H.M.; Maini, P.K.; Carraro, T.; Balocco, S.; Meseguer, A.; Alarcón, T. In Vitro Cell Migration Quantification Method for Scratch Assays. J. R. Soc. Interface 2019, 16, 20180709. [CrossRef]

29. Martinotti, S.; Ranzato, E. Scratch Wound Healing Assay. Methods Mol. Biol. 2020, 2109, 225-229. [CrossRef]

30. Vang Mouritzen, M.; Jenssen, H. Optimized Scratch Assay for In Vitro Testing of Cell Migration with an Automated Optical Camera. J. Vis. Exp. 2018. [CrossRef]

31. Ali Khan, B.; Ullah, S.; Khan, M.K.; Alshahrani, S.M.; Braga, V.A. Formulation and Evaluation of Ocimum Basilicum-Based Emulgel for Wound Healing Using Animal Model. Saudi. Pharm. J. 2020, 28, 1842-1850. [CrossRef] 
32. Manzoureh, R.; Farahpour, M.R. Topical Administration of Hydroethanolic Extract of Trifolium Pratense (Red Clover) Accelerates Wound Healing by Apoptosis and Re-Epithelialization. Biotech. Histochem. 2021, 96, 276-286. [CrossRef]

33. da Silva, L.P.; Reis, R.L.; Correlo, V.M.; Marques, A.P. Hydrogel-Based Strategies to Advance Therapies for Chronic Skin Wounds. Annu. Rev. Biomed. Eng. 2019, 21, 145-169. [CrossRef]

34. Chen, T.-Y.; Wen, T.-K.; Dai, N.-T.; Hsu, S.-H. Cryogel/Hydrogel Biomaterials and Acupuncture Combined to Promote Diabetic Skin Wound Healing through Immunomodulation. Biomaterials 2021, 269, 120608. [CrossRef] [PubMed]

35. Luminita, F.; Cavalu, S.; Miere, F.; Vicaş, S. Formulation, Characterization, and Advantages of Using Liposomes in Multiple Therapies. Pharmacophore 2020, 11, 1-12.

36. Demirci, S.; Doğan, A.; Aydın, S.; Dülger, E.Ç.; Şahin, F. Boron Promotes Streptozotocin-Induced Diabetic Wound Healing: Roles in Cell Proliferation and Migration, Growth Factor Expression, and Inflammation. Mol. Cell. Biochem. 2016, 417, 119-133. [CrossRef]

37. Francesko, A.; Petkova, P.; Tzanov, T. Hydrogel Dressings for Advanced Wound Management. Curr. Med. Chem. 2018, 25, 5782-5797. [CrossRef] [PubMed]

38. Dobjanschi, L.; Luminita, F.; Patay, E.; Tamas, M. Comparative Study of the Morphological and Phytochemical Characterization of Romanian Solidago Species. Pak. J. Pharm. Sci. 2019, 32, 1571-1579.

39. Oza, M.J.; Kulkarni, Y.A. Trifolium Pratense (Red Clover) Improve SIRT1 Expression and Glycogen Content in High Fat Diet-Streptozotocin Induced Type 2 Diabetes in Rats. Chem. Biodivers. 2020, 17, e2000019. [CrossRef]

40. Ahmad, S.; Zeb, A. Phytochemical Profile and Pharmacological Properties of Trifolium Repens. J. Basic Clin. Physiol. Pharmacol. 2020. [CrossRef]

41. Donatis, A.D.; Comito, G.; Buricchi, F.; Vinci, M.C.; Parenti, A.; Caselli, A.; Camici, G.; Manao, G.; Ramponi, G.; Cirri, P. Proliferation Versus Migration in Platelet-Derived Growth Factor Signaling: The Key Role of Endocytosis *. J. Biol. Chem. 2008, 283, 19948-19956. [CrossRef] [PubMed]

42. Benhadou, F.; Mintoff, D.; Del Marmol, V. Psoriasis: Keratinocytes or Immune Cells—Which Is the Trigger? Dermatology 2019, 235, 91-100. [CrossRef] 